\title{
É POSSÍVEL FALAR EM DESENVOLVIMENTO NA CADEIA PRODUTIVA DO AÇAÍ?
}

\section{Otávio Bruno da Silva Ferreira* Juliana Rodrigues Freitas**}

\begin{abstract}
Resumo: $O$ artigo analisa os aspectos teóricos da teoria do desenvolvimento para compreeender se é possível falar em desenvolvimento na cadeira produtiva do açaí. Analisa a forma de extração do fruto e a condição de vida das pessoas responsáveis por tal atividade. Responde a indagação proposta e se propõe um novo formato de desenvolvimento, fundado na pessoa e na observância da melhoria de sua condição de vida, sem descuidar da importância do crescimento econômico, mas diferenciando-o do que se entende por desenvolvimento. Está estruturado em pesquisa qualitativa, de natureza aplicada, do tipo exploratória com utilização de pesquisas bibliográfica e documental.
\end{abstract}

Palavras-chave: Cadeia do Açaí; Crescimento; Desenvolvimento; Sustentável; Includente.

\section{IS IT POSSIBLE TALK ABOUT DEVELOPMENT IN THE AÇAÍ PRODUCTION CHAIN?}

\begin{abstract}
The article analyzes the theoretical aspects of development theory to understand if it is possible to speak in development in the productive chair of açaí. It analyzes the extraction of the fruit and the living conditions of the people responsible for such activity. It responds to the proposed question and proposes a new format of development, based on the person and observing the improvement of their living conditions, without neglecting the importance of economic growth, but differentiating it from what is understood by development. It is structured in qualitative research, exploratory type with the use of bibliographical and documentary researches.
\end{abstract}

Key words: Açaí Chain; Growth; Development; Sustainable; Inclusive.

\footnotetext{
* Mestrando em Direito, Políticas Públicas e Desenvolvimento Regional pelo PPGD do Centro Universitário do Estado do Pará - CESUPA. Juiz do Trabalho Substituto. E-mail: otavio.ferreira@trt8.jus.br

** Doutora em Direito pela Universidade Federal do Pará. Mestre em Direitos Humanos. Professora dos Cursos de Graduação e de Mestrado do Centro Universitário do Pará - CESUPA. E-mail: rodriguesfreitasjuliana@gmail.com
}

Rev. de Direito, Economia e Desenvolvimento Sustentável| e-ISSN: 2526-0057| Porto Alegre | v. 4 | n. 2 | p. 55 - 75 | Jul/Dez. 


\section{INTRODUÇÃO}

A atividade de extração do açaí, fruto da palmeira conhecida como açaizeiro (Euterpe oleracea) vem sofrendo modificações em face do aumento da demanda pelo produto. Outrora, revelava-se como mais uma atividade familiar voltada, no máximo, ao consumo interno, ou seja, dentro do próprio município ou estado. Atualmente, a procura pelo fruto o fez ser considerado como cadeia de valor para o desenvolvimento regional, especificamente no Programa PARA2030 do Governo do Estado do Pará.

Segundo a Pesquisa Agrícola Municipal - PAM 2016 do Instituto Brasileiro de Geografia e Estatística, de 2015 para 2016, no território nacional, a produção de açaí aumentou de 1.008.387 para 1.092.205 toneladas, com aumento de área recolhida de 136.904 para 167.529 hectares, produzindo $\mathrm{R} \$ 4.081 .079$ e $\mathrm{R} \$ 3.932 .497$, respectivamente, em 2015 e 2016.

Na mesma Pesquisa, o Estado do Pará desponta como o principal produtor do fruto, sendo responsável por 98,9\% da produção nacional.

A demanda crescente sem o aparelhamento necessário com questões relacionadas à segurança, propriedade, qualidade de vida e estudo de todos os componentes da cadeia produtiva gera problemas à comunidade ribeirinha, responsável pela extração do produto.

Nesse sentido, "a pressão exercida pelas atividades de alto impacto desestabiliza estas populações, lançando-as na insegurança alimentar e fundiária e com alto impacto em sua qualidade de vida e cultura." (PEABIRU, 2016, p. 16)

A coleta do açaí pode ocorrer sob duas formas: a) cultivado, aquele colhido de área previamente preparada e adequada, a partir de manejo florestal, com tamanho de árvores controladas para o fim de facilitar a extração do produto e; b) extrativo, aquele extraído das várzeas, sem controle do tamanho e da espécie.

O presente artigo parte do levantamento de riscos existentes na cadeia produtiva do açaí extraído nas várzeas e da situação social do "peconheiro", realizado pelo Instituto Peabiru, a partir da celebração de convênio com o Programa Trabalho Seguro do Tribunal Regional do Trabalho da Oitava Região.

O diagnóstico revelou que a atividade de extração do açaí possui uma série de riscos

1 Indivíduo responsável pela extração do açaí. O nome "peconheiro" decorre da utilização da "peconha" para auxiliar na subida na árvore. A "peconha" é um instrumento em formato circular, confeccionado com o uso de folhas do açaizeiro ou com fios plásticos e sintéticos. No processo de subida, o "peconheiro" coloca a "peconha" entre os pés em formato de semicírculo, rodeando a árvore.

Rev. de Direito, Economia e Desenvolvimento Sustentável| e-ISSN: 2526-0057| Porto Alegre | v. 4 | n. 2 | p. 55 - 75 | Jul/Dez. 
relacionados à segurança do trabalho, os quais demandam atenção estatal, bem como identificou a carência de serviços públicos.

A despeito da importância da atividade do peconheiro para o desenvolvimento regional e da existência de riscos em sua atividade, tal situação é desprezada pelos demais componentes da cadeia do açaí - atravessadores, comerciantes, supermercados, "batedores"2, e ignorada pelo consumidor final. A ignorância pelo consumidor final obsta a conscientização e a cobrança por medidas que garantam a eliminação daqueles riscos.

Diante desse cenário, o objetivo do estudo é analisar se é possível falar em desenvolvimento gerado pela cadeia produtiva do açaí. Para tanto, apontam-se como objetivos específicos analisar o que se compreende como desenvolvimento, com destaque para suas características, investigar as estratégias de desenvolvimento regional específicas para a cadeia produtiva do açaí e propor soluções para garantir o desenvolvimento no contexto social.

$\mathrm{O}$ estudo está estruturado da seguinte forma: a) quanto à abordagem, utilizar-se-á de pesquisa qualitativa; b) quanto à natureza, revela-se como pesquisa aplicada, com o intuito de gerar conhecimento para aplicação prática; c) quanto aos objetivos, será do tipo exploratório e; d) quanto aos procedimentos, serão realizadas pesquisas bibliográfica e documental.

O desenvolvimento do artigo partiu de marcos teóricos a respeito do desenvolvimento nas obras de Ignacy Sachs, Desenvolvimento: includente, sustentável, sustentado, e na obra de Amartya Sen, Desenvolvimento como Liberdade. A partir deles foi possível discorrer sobre a noção de desenvolvimento, com diferenciação de crescimento econômico, bem como apontar um modelo de desenvolvimento sustentável, com respeito à pessoa humana e sua condição de vida.

O texto está dividido da seguinte forma: inicia-se com uma abordagem dos marcos teóricos sobre a teoria do desenvolvimento. Em seguida, analisa-se a atividade do peconheiro, com enfoque nos riscos a que estão expostos e na forma de divisão do trabaho. A partir daí responde-se ao questionamento feito no título do presente artigo para, ao final, propor uma modelo de desenvolvimento adequado às peculiaridades regionais, seguindo as considerações finais.

\footnotetext{
2 Batedores de açaí: trabalhadores responsáveis pela transformação do fruto açaí do estado natural (caroço encapado por uma massa de cor vinho escuro) em estado líquido para consumo, por meio da utilização de uma máquina conhecida como batedeira, construída sob o formato cilíndrico, colocada na forma vertical, com abertura nas duas extremidades, sendo colocada pela extremidade superior o fruto em seu estado natural, o qual é batido ao longo do cilindro, até a transformação em suco, despejado pela extremidade inferior.
} 
O escopo do estudo não é esgotar o tema ou discutir sobre todos os instrumentos que podem ser utilizados para promover o desenvolvimento das comunidades diretamente interessadas, mas servir para reflexão de novos estudos sobre a temática na tentativa de criar uma base de informações e discussões que possam ser utilizadas pelos peconheiros na defesa de seus interesses e pelo Poder Público na proposição de políticas públicas.

\section{ASPECTOS TEÓRICOS SOBRE DESENVOLVIMENTO}

A palavra desenvolvimento abarca uma série de significados, a depender da temática em que é tratada, da heterogeneidade cultural da comunidade que a examina e do adjetivo que a qualifica, daí podermos falar em desenvolvimento humano, sustentável, econômico, dentre outros, sem falar que cada uma das conotações pode apresentar mais de uma interpretação. Assim, é bastante difícil a tarefa de defini-la, para todos os países e povos, em termo unívoco.

Segundo Anjos Filho (2009), a palavra desenvolvimento surgiu entre os séculos XII e XIII, e o seu sentido inicial era o de revelar, expor, passando a significar a progressão de estágios mais simples, inferiores, para outros mais complexos, superiores, apenas por volta de 1850.

Para Sachs (2008), o desenvolvimento não se presta a ser encapsulado em fórmulas simples e seu conceito tem evoluído durante os anos, incorporando experiências positivas e negativas, refletindo as mudanças nas configurações políticas e as modas intelectuais.

Inicialmente, o termo era objeto de estudo apenas da economia, mas atualmente é tratado como interdisciplinar por envolver aspectos jurídicos, políticos, culturais e sociológicos. Nesse cenário, segundo Anjos Filho (2009) o conteúdo do termo desenvolvimento é dinâmico e tem se ampliado acompanhando a evolução histórico-social. Dessa forma, pode-se afirmar que nos dias atuais trata-se de uma palavra inegavelmente plurívoca.

Dentre as diversas abordagens do fenômeno, interessante a análise de sua relação com o crescimento econômico, por ter sido a economia a primeira ciência a se debruçar sobre o aspecto.

No momento da expansão mercantilista e das grande navegações, o desenvolvimento se identificava com o poder econômico, que era a principal representação do poder nacional. No século XX, deu lugar à preocupação com a noção de desenvolvimento, especialmente a partir das abordagens que tinham o propósito de efetivar o bem-estar social. A partir daí, a

Rev. de Direito, Economia e Desenvolvimento Sustentável| e-ISSN: 2526-0057| Porto Alegre | v. 4 | n. 2 | p. 55 - 75 | Jul/Dez. 
teoria do desenvolvimento se tornou um desdobramento da teoria econômica, podendo falar em desenvolvimento econômico.

Após a Segunda Guerra Mundial, num quadro de extrema desigualdade e atraso econômico, o debate avançou para outras áreas do conhecimento por meio do debate político a respeito das causas e consequências do conflito (ANJOS, 2009).

Assim, identifica-se um cenário, no qual o desenvolvimento identificou-se meramente com o crescimento econômico e outro, no qual o crescimento deve ser aferido por determinados e específicos indicadores, que vão além da perspectiva econômica.

Segundo Anjos Filho (2009) o desenvolvimento econômico pressupõe como condição necessária - mas não suficiente - o crescimento. Isso porque o crescimento econômico por si só não assegura o desenvolvimento, já que é possível que o aumento da produção, da riqueza não se dê em benefício da economia como um todo ou da melhoria das condições da população em geral. Esse resultado pode ocorrer por força de diversos fatores, dentre os quais a acumulação excessiva de riqueza de determinados grupos ou elites detentores da propriedade dos bens de produção, aumentando a concentração de renda, bem como a existência de altas taxas de desemprego em decorrência da informatização, robotização e mecanização dos setores de produção e serviços.

Assim, é possível diferenciar e afirmar que o crescimento corresponde a um dado objetivo de aumento de determinado indicador que afere quantitativamente o produto econômico. De outro lado, a noção de desenvolvimento está vinculada à melhoria qualitativa das condições de vida da população, por meio da transformação da economia, que passaria a corresponder a um modelo moderno, eficiente, e inclusivo.

Para tanto, identifica-se que o processo de desenvolvimento altera não só as estruturas econômicas e produtivas, mas também as sociais, institucionais e políticas, significando o aumento da produção acompanhado do incremento da renda e da capacidade econômica da população.

Perroux (1964), pautado na interdisciplinariedade e em sua concepção de desenvolvimento como mudança de estrutura, afirma que o crescimento é o aumento de um indicador de dimensão, o produto interno bruto ou líquido, que provoca uma melhoria puramente quantitativa. Desenvolvimento designa a combinação de mudanças mentais e sociais de uma população que a tornam apta a fazer crescer, de maneira cumulativa e permanente, o seu produto real global.

Rev. de Direito, Economia e Desenvolvimento Sustentável| e-ISSN: 2526-0057| Porto Alegre | v. 4 | n. 2 | p. 55 - 75 | Jul/Dez. 
A contribuição de Perroux (1964) está relacionada à análise das economias subdesenvolvidas com a finalidade de propor estratégias de desenvolvimento adaptadas às suas especificidades, rompendo com os ideias de desenvolvimento como parâmetro universal de norte ao sul.

Para Ignay Sachs (2008, p. 13)

\begin{abstract}
O desenvolvimento, distinto do crescimento econômico, cumpre esse requisito, na medida em que os objetivos do desenvolvimento vão bem além da mera multiplicação da riqueza material. O crescimento é uma condição necessária, mas de forma alguma suficiente (muito menos é um objetivo em si mesmo), para se alcançar a meta de uma vida melhor, mais feliz e mais completa para todos.
\end{abstract}

Continua afirmando que "igualdade, equidade e solidariedade estão, por assim dizer, embutidas no conceito de desenvolvimento, com consequências de longo alcance para que o pensamento econômico sobre o desenvolvimento se diferencie do economicismo redutor." (SACHS, 2008, p. 14). E "Em vez de maximizar o crescimento do PIB, o objetivo maior se torna promover a igualdade e maximizar a vantagem daqueles que vivem nas piores condições, de forma a reduzir a pobreza, fenômeno vergonhoso, porquanto desnecessário, no nosso mundo de abundância." (SACHS, 2008, p. 14)

No plano interno, Eros Roberto Grau (1997) acentua que o desenvolvimento pressupõe mudanças dinâmicas de natureza quantitativa e qualitativa e um processo de mobilidade social contínuo, ocorrendo um salto de uma estrutura social para outra e a elevação do nível econômico, cultural e intelectual de toda a comunidade. Daí porque entende que o crescimento, que implica noção quantitativa, representa apenas uma parcela do desenvolvimento e não se confunde com o mesmo.

Gilberto Bercovici (1998), por sua vez, destaca o papel central das reformas estruturais na política dos países subdesenvolvidos, constituindo condição prévia e necessária de desenvolvimento, para o qual é preciso uma atuação ampla e intensa do Estado como coordenador do planejamento, visando modificar as estruturas socioeconômicas e a distribuição e descentralização da renda, de forma a integrar toda a população no âmbito social e político.

Pinto Ferreira (1993) entende que o desenvolvimento é um processo global de mudança social que implica em transformações da sociedade e da economia, composto de três aspectos básicos: aumento real da renda per capita, longa duração do processo e melhor distribuição dos bens da vida, resultando no aprimoramento do bem-estar dos membros da comunidade.

Rev. de Direito, Economia e Desenvolvimento Sustentável| e-ISSN: 2526-0057| Porto Alegre | v. 4 | n. 2 | p. 55 - 75 | Jul/Dez. 
Celso Furtado (1980), destaca que a História contemporânea registra a utilização do conceito de desenvolvimento em dois sentidos distintos. O primeiro é relativo ao aumento da eficácia do sistema de produção de uma sociedade através da acumulação e do progresso das técnicas; o segundo diz respeito ao grau de satisfação das necessidades humanas, sejam elas elementares, tais como habitação, vestuário, alimentação e expectativa de vida, ou sejam elas necessidades menos nítidas, compreensíveis apenas a partir de determinado contexto cultural.

Destaca que o aumento da eficácia do sistema de produção, dado que normalmente é tido como principal indicador do desenvolvimento, não constitui condição suficiente para o alcance da melhor satisfação das necessidades humanas, e que a inserção de técnicas mais sofisticadas pode, até mesmo, provocar a degradação das condições de vida da população em geral. De outro lado, essas mesmas condições podem obter melhoras sem qualquer alteração nos processos produtivos. Porém, verdadeiro desenvolvimento só se verifica se há benefícios para o conjunto da população.

É importante destacar que desenvolvimento, dentre desse contexto, terá um caráter dinâmico, pois as necessidades de determinada comunidade não serão tidas como universalizantes. É que cada comunidade terá sua escala própria de valores. Assim, somente pela análise do aumento da qualidade de vida de seus componentes é que poderá acreditar em verdadeiro desenvolvimento.

Para tanto, os indicadores clássicos de desenvolvimento, como o produto nacional global, o produto interno bruto ou a renda per capita, não serão suficientes para a exata compreensão de desenvolvimento. Justifica-se a incoerência em face daqueles indicadores terem sido adotados em decorrência de processos econômicos e não refletirem indicadores sobre melhoria da qualidade de vida das pessoas, no campo social, humano e cultural. Faz-se necessário, portanto, a implementação e aplicação de novos indicadores que considerem a melhoria de qualidade de vida do ser humano como principal objetivo do desenvolvimento.

Como anota Anjos Filho (2009), o subdesenvolvimento pode ser identificado com a situação na qual o crescimento econômico não ocorre, ou, quando ocorre: é irregular; está amparado, muitas vezes, por processos ambientalmente condenáveis e tecnologicamente atrasados; não se dá em ritmo suficiente para acompanhar o aumento demográfico; resulta em maior concentração de riqueza e renda nas mãos de uma elite minoritária, e, consequentemente, no aumento ou na manutenção de grandes contingentes de pessoas em situação de pobreza, promovendo a deteriorização das condições sociais.

Rev. de Direito, Economia e Desenvolvimento Sustentável| e-ISSN: 2526-0057| Porto Alegre | v. 4 | n. 2 | p. 55 - 75 | Jul/Dez. 
Pelos argumentos expostos, denota-se que o desenvolvimento está além da perspectiva econômica, representando um processo mais amplo e abrangente do que o crescimento quantitativo da economia.

Além disso, identificou-se que é necessária atuação positiva do Estado para que ocorra o desenvolvimento. Nesse contexto, importante a lição de Ignacy Sachs (2008, p. 11), para quem:

O Estado nacional tem três funções principais:

a) A articulação de espaços de desenvolvimento, desde o nível local (que deve ser ampliado e fortalecido) ao transnacional (que deve ser objeto de uma política cautelosa de integração seletiva, subordinada a uma estratégia de desenvolvimento endógeno);

b) A promoção de parcerias entre todos os atores interessados, em torno de um acordo negociado de desenvolvimento sustentável;

c) A harmonização de metas sociais, ambientais e econômicas, por meio do planejamento estratégico e do gerenciamento cotidiano da economia e da sociedade, buscando um equilíbrio entre diferentes sustentabilidades (social, cultural, ecológica, ambiental, territorial, econômica e política) e as cinco eficiências (de alocação, de inovação, a keynesiana, a social e a ecoeficiência).

O mesmo autor (2008, p. 12) analisa estratégia de desenvolvimento endógeno, que passa pela análise das necessidades de determinada comunidade ao desenvolvimento de estratégias próprias para o crescimento. Nesse contexto, importante o debate a respeito do conceito de desenvolvimento sustentável, baseado nos pilares da endogeneidade (oposta ao crescimento mimético): autoconfiança (oposta à dependência), orientação por necessidades (em oposição à orientação pelo mercado), harmonia com a natureza e abertura à mudança institucional.

Ignay Sachs contribuiu para o desenvolvimento do conceito de desenvolvimento sustentável. Para ele:

Os cinco pilares do desenvolvimento sustentável são:

a - Social, fundamental por motivos intrínsecos quanto instrumentais, por causa da perspectiva da disrupção social que paira de forma ameaçadora sobre muitos lugares problemáticos de nosso planeta;

b- Ambiental, com as suas duas dimensões (os sistemas de sustentação da vida como provedores de recursos e como 'recipientes' para a disposição de resíduos);

c- Territorial, relacionada à distribuição espacial dos recursos, das populações e das atividade;

d - Econômico, sendo a viabilidade econômica a conditio sine qua non para que as coisas aconteçam;

e- Político, a governança democrática é um valor fundador e um instrumento necessário para fazer as coisas acontecerem; a liberdade faz toda a diferença." (SACHS, 2008, p. 15-16)

Acrescenta ainda que:

Rev. de Direito, Economia e Desenvolvimento Sustentável| e-ISSN: 2526-0057| Porto Alegre | v. 4 | n. 2 | p. 55 - 75 | Jul/Dez. 


\begin{abstract}
A transição para o desenvolvimento sustentável começa com o gerenciamento de crises, que requer uma mudança imediata de paradigma, passando-se do crescimento financiado pelo influxo de recursos externos e pela acumulação de dívida externa para o do crescimento baseado na mobilização de recursos internos, pondo as pessoas para trabalhar em atividades com baixo conteúdo de importações e para aprender a 'vivir con lo nuestro'. (SACHS, 2008, p. 17)
\end{abstract}

Nesse contexto, elenca como condições necessárias para se levar à frente o crescimento induzido pelo emprego: a) a capacidade local de planejamento, entendido como a capacidade de identificação de gargalos e de recursos ociosos capazes de superá-los; b) estímulo à capacidade de mobilizar recursos e iniciativas locais; c) reabilitação do sistema financeiro nacional, para dotá-lo de um mínimo de capacidade para atender às necessidades das empresas e do financiamento de obras públicas, sem excluir o recurso (em casos excepcionais) à quase-moeda e à programação do escambo; d) uma reforma fiscal que criasse um Imposto de Valor Adicionado progressivo sobre o consumo: haveria isenção para os bens essenciais, mas ele teria forte incidência sobre artigos de luxo, conforme sugerido por Kalecki, no seu texto sobre a Índia; os salários baixos seriam subsidiados com este imposto; (SACHS, 2008, p. 17-18)

Nota-se, portanto, o apontamento de valiosos instrumentos que podem ser utilizados para o desenvolvimento de determinada comunidade, com fundamento na geração de emprego digno e com observância das peculiaridades regionais, fazendo com que as estratégias de desenvolvimento sejam pensadas a partir das necessidades básicas da população e não a partir de um modelo hegemônica tido como adequado.

\title{
2 DIAGNÓSTICO SOBRE A VIDA DO PECONHEIRO
}

O ator social responsável pela coleta do açaí é o peconheiro. A atividade de coleta de açaí revela-se como atividade tradicional, de conhecimento por todos os que compõem a comunidade e é repassada de geração em geração, geralmente, à criança do sexo masculino.

No diagnóstico realizado pelo Peabiru (2016, pp. 7-8) foram identificadas, dentre outras, as seguinte situações relacionadas à atividade extrativa do açaí:

A FUNDACENTRO e Instituto Peabiru observam que a atividade é uma das mais perigosas do Brasil;

O que mais chama a atenção é o grau de precariedade da atividade;

Os riscos se multiplicam se considerarmos que, num dia de pico de safra há algo

Rev. de Direito, Economia e Desenvolvimento Sustentável| e-ISSN: 2526-0057| Porto Alegre | v. 4 | n. 2 | p. 55 - 75 | Jul/Dez. 
próximo de 1 milhão de subidas em açaizeiros;

Uma atividade típica da agricultura familiar se tornou uma cadeia de valor global, com características de uma commoditie, abrangendo um número estimado de mais de 120 mil famílias, envolvendo de 2 a 4 trabalhadores por família;

É total a invisibilidade da segurança do trabalho perante o consumidor final o que faz que os elos fortes da cadeia de valor - indústrias, atacadistas, varejistas e batedores (na região) não se responsabilizem com a segurança do trabalhador;

A longo prazo, especialmente para jovens, o esforço físico de subir na árvore, resultará em consequências permanentes para suas vidas, especialmente afetando os pés e as pernas.

Sobre a quantidade de famílias envolvidas na atividade, no diagnóstico citado, após entrevista com a população ribeirinha, foi possível destacar que:

Pode-se estimar, de maneira bem genérica, que num dia de safra, se cento e vinte mil coletores subirem nos açaizeiros em oito a dez árvores cada um, a grosso modo, isto significaria algo próximo a 1 milhão de subidas em açaizeiros num dia de pico de safra. Jovens mais ágeis podem subir em mais de 20 pés de açaizeiros e, ainda, pulam, de uma árvore a outra, expondo-se a riscos ainda maiores. A dimensão deste dado, ainda que seja impreciso, por si só, expõe o potencial para a segurança do trabalhador extrativista - o peconheiro. (PEABIRU, 2016, p. 23)

Além disso, inexiste regulamentação específica de proteção ao peconheiro. No Estado do Pará, a legislação existente, Decreto $n^{\circ}$. 326, de 20.1.2012, refere-se exclusivamente a qualidade do produto para consumo, sem preocupação com questões de segurança do trabalhador responsável pela colheita.

A partir de entrevistas realizadas pelo Peabiru, foram detectadas as seguintes situações:

$100 \%$ de informalidade nas relações de trabalho;

$89 \%$ dos entrevistados disseram que alguém de sua família ou meeiro já sofreu um acidente de trabalho em seu açaizal;

$54 \%$ dos casos, o acidente teve como consequência a internação do paciente;

$62 \%$ dos acidentes demandaram tempo de afastamento entre 10 a 60 dias;

Alta evasão escolar no período da safra do açaí, o que corrobora para que a região tenha os piores índices educacionais do Brasil; e

Aumento do consumo de álcool, drogas e prostituição. (PEABIRU, 2016, p. 8)

Em decorrência da inexistência de política pública apropriada, aliada a ausência de regulamentação da atividade, também foram identificados os seguintes problemas:

Estas populações sofrem a falta de acesso a: a) serviços básicos (educação, saúde, energia, transporte etc.); b) segurança fundiária (acirrada pela grilagem, garimpo e quadrilhas de roubo de recursos naturais do tipo "sem tora"); c) acesso ao mercado e oportunidades econômicas (sem capacidade de decisão nas cadeias de valor que participam e colaborando, geralmente, com relações informais de trabalho); e d) conhecimento técnico, crédito, assistência técnica (sempre insuficientes) e

Rev. de Direito, Economia e Desenvolvimento Sustentável| e-ISSN: 2526-0057| Porto Alegre | v. 4 | n. 2 | p. 55 - 75 | Jul/Dez. 
capacidade para se beneficiar da participação potencial na economia formal; entre outras questões. Ainda, são afetadas pela expansão do agronegócio e da fronteira econômica, na sua segurança alimentar e hídrica. (PEABIRU, 2016, pp. 16-17)

Especificamente quanto aos riscos físicos suportados pelo peconheiros, foram diagnosticados os seguintes riscos separados de acordo com a parte do corpo atingida:

Cabeça: picadas e ataques de abelhas e cabas (vespas e marimbondos), e ferrada de insetos (lacraias, escorpiões, aranhas etc.). Ataques de aves que nidificam no local, queda de faca (terçado) na cabeça de quem está no chão, esperando o cacho do açaí; Especialmente em relação aos olhos, o maior problema é a sujeição a espetadas das ponta de galhos e folhas;

Braços: fraturas por conta de queda, escoriações pra descer do açaí, corte nos braços pela faca;

Ombros e peito: rasgadura, distensão muscular, causada pelo esforço físico excessivo;

Costas e nádegas: furo da ponta da facas, furos em função dos tocos das árvores velhas;

Pernas: cortes, picadas de cobra, ferimento com machado na época do manejo, além do esforço físico de segurar na árvore, levando ao arqueamento das pernas; e

Pés: calos, ferradas de peixe arraia, choque do peixe-elétrico (poraquê), picadas de aranha, pisão (pisada forte) em tocos. (PEABIRU, 2016, 46)

Os riscos podem ser melhor compreendidos a partir da análise da rotina diária do peconheiro, desde o momento que se organiza para se deslocar ao local onde fará a colheita até o momento da retirada do fruto do cacho. Nesse sentido, consta com detalhes a referida rotina:

a. A caminhada em meio ao terreno alagadiço de várzea, onde existem poraquês, cobras, escorpiões e outros animais, além do risco de estrepe, prender o pé e outros. Trata-se de atividade que exige bom preparo físico, especialmente porque se carregam paneiros (cestos), sejam os vazios, empilhados, sejam os cheios de açaí. Os riscos se agravam quando o extrativista está sozinho e não quem possa socorrêlo;

b. A passagem por pinguelas e outras tábuas e pontes improvisadas, para cruzar cursos d'água ou acessar os trapiches (portos, em que troncos de miriti ou outros servem de passarela), que geralmente são escorregadias, por conta do limo, lama ou vegetação que está sobre estas superfícies, oferece risco de tombo, baque, e mesmo ferir-se com o facão na queda;

c. A rotina de remar longos trechos sob o sol e, eventualmente, passando em regiões onde há galhadas, sujeitas a cortes, encontro com animais peçonhentos, além de abelhas, formigas etc. e levar os paneiros (cestos) vazios até o local da coleta resulta em atividade que pode significar muitas horas, inclusive em períodos de baixa iluminação. Em algumas localidades, sujeita-se, ainda, a momentos de maré forte, banzeiro resultado de ventanias ou correntezas fortes, chuvas etc.;

d. A preparação da subida no açaizeiro, com a limpeza do local, a preparação da peconha (o laço feito da folha do açaizeiro ou outro material plástico);

e. A subida no açaizeiro e o grande esforço que se faz utilizando pés, pernas, braços e mãos, a colheita do cacho, a descida com um ou mais cachos, e os riscos de quebra de árvore, encontro com animais peçonhentos e, na descida, furar nos antigos troncos de açaizeiros (empalamento);

Rev. de Direito, Economia e Desenvolvimento Sustentável| e-ISSN: 2526-0057| Porto Alegre | v. 4 | n. 2 | p. 55 - 75 | Jul/Dez. 
f. A troca de árvores, sem descer, com e sem cachos é sem dúvida a atividade de maior risco, lembrando-se que o peconheiro está, usualmente, com um facão descoberto numa das mãos ou enfiado na bermuda;

g. A atividade de derriça dos frutos do cacho e a montagem dos paneiros, ao seu transporte em área de várzea até a embarcação ou a casa é um trabalho que exige destreza, e rapidez. Muitas vezes é realizado por mulheres que acompanham os jovens e os homens ao local de colheita; e

h. A baldeação dos paneiros do casquinho (pequeno barco) para barcos maiores ou um dos portos para juntar com demais cargas, atividade que é realizada, em geral, por diversos membros da família. (PEABIRU, 2016, pp. 50-51)

A despeito de tal situação, inexiste política pública voltada especificamente para a garantia de segurança na atividade de extrativismo de açaí em várzea.

Os próprios peconheiros pesquisados revelaram a intenção de obter melhoria em sua atividade, demonstrando consciência dos riscos que lhe cercam. Segundo Peabiru (2016, p. 46)

Todos os presentes afirmaram que estão propensos a utilizar o que estiver disponível para aumentar a segurança da atividade, mas reconhecem que, provavelmente, não haja apenas uma única solução. Entendem que é necessária a combinação de um maior manejo dos açaizais, o apoio com linhas de crédito para a entressafra, a maior assistência técnica e o uso de equipamentos de extração do cacho de açaí.

Tal situação representa que uma atividade importante para o desenvolvimento regional acaba por repercutir no aumento da insegurança da população tradicional que executa sua exploração, sem a devida atenção pelos órgãos governamentais.

\section{A DIVISÃO DO TRABALHO NA EXTRAÇÃO DO AÇAÍ}

Segundo Marinho (2005), a extração do açaí é uma atividade que envolve homens, mulheres e crianças, sem uma rígida divisão do trabalho, pois todos os extratores envolvidos, independentemente de idade e gênero, podem se dedicar a qualquer etapa do processo extrativo, ainda que, na área estudada, tenha se observado que as mulheres se dediquem mais a debulha, enquanto os homens e as crianças ocupam-se preferencialmente com a extração propriamente dita.

Identifica-se, portanto, “a exposição de dezenas de milhares de jovens (número que precisa ser melhor avaliado pelos órgãos competentes), muitos sem idade para trabalhar, tanto homens, como mulheres, a uma atividade profissional que exige grande esforço e é de alto risco" (PEABIRU, 2016).

É preciso também diferenciar a realização de agricultura familiar da produção em cadeia. É que a atividade extrativista realizada inicialmente para o consumo próprio tomou 
proporções mercadológicas exigindo o aumento da produção e, por consequência, interferindo no aumento de subidas e descidas no açaizeiro (Euterpe olereacea), com aumento da exposição a riscos e acidentes.

Segundo PEABIRU (2016):

o jovem, que é mais ágil, mais leve, ousado e mais corajoso, sobe 8 rapidamente em uma ou poucas árvores de açaí e colhe o necessário para o consumo diário da família. Entretanto, na última década, com o crescimento exponencial da demanda pelo vinho (polpa) de açaí, a coleta passou a atender, não apenas o consumo da própria família ou localidade, ou o limitado mercado regional, que consume o açaí fresco, in natura, para se transformar em uma cadeia de valor de interesse global, envolvendo novos elos de cadeia de valor (indústrias processadoras, atacadistas, varejistas e outros.

Segundo Marinho (2005), a distribuição de atividades é definida, em linhas gerais, de acordo com o sexo e a idade de cada membro do grupo, o que não significa um rígido seccionamento de funções entre o chefe da família, as crianças (geralmente meninos) e a esposa, ainda que esta, em geral, desempenhe as atividades consideradas menos pesadas no açaizal, mas, por outro lado, execute os serviços domésticos praticamente sozinha.

A respeito do trabalho de crianças na cadeia do açaí, Peabiru (2016), na pesquisa realizada no rio médio Canaticu, enfatizou que

A questão do trabalho infantil não foi objeto do trabalho, mas mostrou-se presente no ambiente, necessitando ser estudada na cadeia de valor do açaí, pois numa atividade tradicional, o mais ágil, leve e ousado, sobe rapidamente e colhe o necessário para o consumo diário da família. E, diante de um mercado crescente, quem antes subia diariamente uma ou duas vezes no açaizeiro, agora sobe dez ou mais vezes e, ainda, pula, de uma árvore a outra.

Da mesma forma, na pesquisa realizada no rio médio Pracuúba, Marinho (2005), identificou que

Estas [crianças], sobretudo do sexo masculino, são iniciadas precocemente na extração do açaí. O processo de aprendizagem em geral começa aos 6, 7 anos de idade. Nesta ocasião, os meninos começam a dar seus primeiros saltos naqueles açaizeiros baixinhos, normalmente com o incentivo do pai, que lhe dá algumas instruções elementares, como ter cuidado para a peconha não sair dos pés e os braços não escaparem do fino caule da palmeira. Com isto, a partir de 8, 9 anos de idade, um pouco mais fortes fisicamente, essas crianças já são ágeis coletoras, com habilidade e coragem invejáveis. Além dessas qualidades, um outro aspecto que atribui importância central à mão-de-obra infantil é o reduzido peso das crianças. Esta característica permite a elas escalarem praticamente qualquer palmeira, inclusive aquelas que os adultos não conseguem porque são mais pesados. Deste modo, percebe-se que, embora não tenham a mesma resistência de um extrator experiente, as crianças, em certas ocasiões, mostram-se mais eficientes, ainda que expostas a maiores riscos, porque dificilmente voltam de uma palmeira antes de

Rev. de Direito, Economia e Desenvolvimento Sustentável| e-ISSN: 2526-0057| Porto Alegre | v. 4 | n. 2 | p. 55 - 75 | Jul/Dez. 
extrair seu fruto. Por esta importância, não se verifica localmente nenhuma preocupação relativa às implicações que o massivo uso da mão-de-obra infantil pode acarretar para o crescimento das crianças.

Nota-se, portanto, a exploração de mão de obra infantil na cadeia produtiva do açaí, sem a preocupação do quanto tal exploração acarretará no retardo e prejuízo ao desenvolvimento físico e intelectual da criança e sem a devida observância da condição peculiar de pessoa em desenvolvimento.

\section{4 É POSSÍVEL FALAR EM DESENVOLVIMENTO?}

A forma e a exigência de colheita do açaí foram alteradas significativamente. Antes, o ribeirinho retirava o fruto para consumo próprio e, às vezes, para um pequeno comércio local. A demanda crescente pelo fruto do açaizeiro aumentou em números exponenciais a necessidade de subidas e descidas na árvores.

De outro lado, o crescimento da demanda não foi acompanhado por uma preocupação com a vida e a segurança do trabalhador extrativista, importando tão somente o produto fornecido. Assim, os riscos da atividade aumentaram, sem que fossem feitos estudos sobre métodos de sua eliminação e mitigação. Além disso, o lucro obtivo no mercado não foi repassado ao produtor primário, que entregava seus produtos nas mãos de atravessadores e, no mais complexo sistema, em cooperativas.

Desse modo, a despeito do aumento do trabalho, não houve aumento da renda. Tal situação demandou que os demais membros da família, crianças e adolescentes, também participassem do ciclo produtivo, com objetivo de aumentar a produção e atender o mercado interno e externo.

Nesse cenário, é possível identificar a assertiva de Sen (2000, p. 22), para quem "a privação de liberdade econômica, na forma de pobreza extrema, pode tornar a pessoa uma presa indefesa na violação de outros tipos de liberdade".

Sen (2000, p. 22), tem a "visão do desenvolvimento como um processo integrado de expansão de liberdades substantivas interligadas." Ou seja, o desenvolvimento da cadeia produtiva do açaí deveria propiciar melhoria na qualidade de vida dos peconheiros em sentido substancial. Ou melhor, a "visão de liberdade aqui adotada envolve tanto os processos que permitam a liberdade de ações e decisões como as oportunidades reais que as pessoas têm,

Rev. de Direito, Economia e Desenvolvimento Sustentável| e-ISSN: 2526-0057| Porto Alegre | v. 4 | n. 2 | p. 55 - 75 | Jul/Dez. 
dadas as suas circunstâncias pessoais e sociais.” (SEN, 2000, p. 30)

Especificamente sobre o trabalho infantil, Sen (2000, pp. 44-45) esclarece que "as piores violações da norma contra o trabalho infantil provêm da escravidão em que na prática vivem as crianças de famílias desfavorecidas e do fato de elas serem forçadas a um emprego que as explora (em vez de serem livres e poderem frequentar a escola).

Como dito acima, é imprescindível que a população tradicional seja devidamente esclarecida sobre os riscos a que estão expostas as suas crianças e seus jovens, para que possam, dentro de suas possibilidades, retirá-los da cadeia produtiva, por mais que isso signifique, em certo ponto, redução da produção. Nesse sentido, Sen (2000, p. 46) afirma que:

Se um modo de vida tradicional tem de ser sacrificado para escapar-se da pobreza devastadora ou da longevidade minúscula (que é como vivem muitas sociedades tradicionais há milhares de anos), então são as pessoas diretamente envolvidas que têm de ter a oportunidade de participar da decisão do que deve ser escolhido.

Amartya Sen estabelece cinco ideais de liberdades instrumentais. Dentre elas, podemos destacar, para o contexto analisado, a liberdade como oportunidade social e a liberdade como segurança protetora. Entende que oportunidades sociais:

São as disposições que a sociedade estabelece nas áreas de educação, saúde, etc., as
quais influenciam a liberdade substantiva de o indivíduo viver melhor. Essas
facilidades são importantes não só para a condução da vida privada (como por
exemplo levar uma vida saudável, livrando-se de morbidez evitável e da morte
prematura), mas também para uma participação mais efetiva em atividades
econômicas e políticas. Por exemplo, o analfabetismo pode ser uma barreira
formidável à participação em atividades econômicas que requeiram produção
segundo especificações ou que exijam rigoroso controle de qualidade (uma
exigência sempre crescente no comércio globalizado). De modo semelhante, a
participação política pode ser tolhida pela incapacidade de ler jornais ou de
comunicar-se por escrito com outros indivíduos envolvidos em atividades políticas.
SEN (2000, p. 55)

Identifica-se a necessidade de viabilizar a referida liberdade na vida das crianças e dos adolescentes para que possam, por meio da educação, romper com círculo vicioso de miséria e opressão, que os impede de sonhar diferente, de sonhar com algo melhor, pois não se consegue querer algo que sequer se conhece. Daí porque é imprescindível que crianças e adolescentes tenham acesso à educação para que possam se desenvolver como cidadão, com participação na vida política e com capacidade plena para a tomada de suas decisões.

De outro lado, outro aspecto de liberdade é a segurança protetora que, para ele: 
É necessária para proporcionar uma rede de segurança social, impedindo que a população afetada seja reduzida à miséria abjeta e, em alguns casos, até mesmo à fome e à morte. A esfera da segurança protetora inclui disposições institucionais fixas, como benefícios aos desempregados e suplementos de renda regulamentares para os indigentes, bem como medidas ad hoc, como distribuição de alimentos em crise de fome coletiva ou empregos públicos de emergência para gerar renda para os necessitados. (SEN, 2000, p. 56)

Por fim, acrescenta SEN (2000, p. 143), que:

\begin{abstract}
O problema da desigualdade realmente se magnifica quando a atenção é desviada da desigualdade de renda para a desigualdade na distribuição de liberdades substantivas e capacidades. Isso ocorre principalmente devido à possibilidade de algum 'acoplamento' de desigualdade de renda, de um lado, e vantagens desiguais na conversão de rendas em capacidades, de outro. Este último aspecto tende a intensificar o problema da desigualdade já refletido na desigualdade de renda. Por exemplo, uma pessoa incapacitada, doente, idosa ou que apresenta alguma outra desvantagem pode, por um lado, ter dificuldade para auferir uma renda apropriada e, por outro, também enfrentar dificuldades ainda maiores para converter renda em capacidades e em uma vida satisfatória. Os próprios fatores que podem impossibilitar uma pessoa de encontrar um bom emprego e ter uma boa renda (como a incapacidade) podem deixá-la em desvantagem na obtenção de uma boa qualidade de vida até mesmo com um bom emprego ou boa renda.
\end{abstract}

A análise da existência de desigualdade de renda e desigualdade na distribuição de liberdade substanciais acabam por prejudicar o desenvolvimento em outras áreas.

Ignacy Sachs (2008, p. 35) aponta que:

O desenvolvimento pretende habilitar cada ser humano a manifestar potencialidades, talentos e imaginação, na procura da auto-realização e da felicidade, mediante empreendimentos individuais e coletivos, numa combinação de trabalho autônomo e heterônomo e de tempo dedicado a atividades não produtivas.

A boa sociedade é aquela que maximiza essas oportunidades enquanto cria, simultaneamente, um ambiente de convivência e, em última instância, condições para a produção de meios de existência (livelihoods) viáveis, suprindo as necessidades materiais básicas da vida - comida, abrigo, roupas - numa variedade de formas e cenários - famíias, parentelas, redes, comunidades.

Nesse contexto, identifica-se, a partir de marcos teóricos específicos, que a cadeia do açaí não produz desenvolvimento para a população que está envolvida, sendo necessário discutir a temática a fim de identificar meios, instrumentos e ações pertinentes que possam redirecionar o enfoque do crescimento meramente econômico para o desenvolvimento da população local.

Destaca-se ainda que a população envolvida na cadeia do açaí, especificamente os peconheiros, carecem de acesso aos serviços básicos de saúde e educação, acesso ao mercado, conhecimento técnico e incentivos finanaceiros. Assim, o crescimento econômico não foi 
acompanhado de um crescimento da melhoria da qualidade de vida das pessoas, ou seja, não representou, de fato, desenvolvimento.

\title{
5 APONTAMENTOS PARA UM DESENVOLVIMENTO SUSTENTÁVEL E INCLUDENTE
}

Com o intuito de compreender um modelo adequado de desenvolvimento é importante conhecer as bases que devem ser revistas e redirecionadas. Isto porque, de acordo com Sachs (2008, p. 35)

\begin{abstract}
As formas viáveis de produção de meios de existência não podem se apoiar em esforços excessivos e extenuantes dos seus produtores, em empregos mal pagos e realizados em condições insalubres, na provisão inadequada de serviços públicos e em padrões subumanos de habitação.
\end{abstract}

No caso da cadeia produtiva do açaí, identicou-se que o modelo é pautado na exploração do peconheiro, que se expõe à uma série de riscos, com remuneração inadequada e não compatível com o grau de risco existente em sua atividade, bem como em ambiente de trabalho insalubre, sem a existência de recursos e serviços públicos básicos.

Assim, é premissa a alteração do modelo de exploração econômico. Como instrumento de alteração, destaca-se a aplicação do modelo de desenvolvimento sustentável. Para Sachs (2008, p. 36)

\footnotetext{
O desenvolvimento sustentável obedece ao duplo imperativo ético da solidariedade com as gerações presentes e futuras, e exige a explicitação de critérios de sustentabilidade social e ambiental e de viabilidade econômica. Estritamente falando, apenas as soluções que considerem estes três elementos, isto é, que promovam o crescimento econômico com impactos positivos em termos sociais e ambientais, merecerem a denominação de desenvolvimento.
}

A ideia de desenvolvimento está relacionada a melhoria das condições de vida, com a geração de emprego, redução da pobreza e da desigualdade. Nesse cenário, na linha do entendimento de Amartya Sen, o desenvolvimento pode ser redefinido em termos da universalização e do exercício efetivo de todos os direitos humanos: políticos, civis e cívicos; econômicos, sociais e culturais; bem como direitos coletivos ao desenvolvimento, ao ambiente etc. Embora os direitos sejam indivisíveis, deve ser dado um status especial ao direito do trabalho, visto o seu duplo valor, intrínseco, mas também instrumental, já que o trabalho decente abre o caminho para o exercício de vários outros direitos. (SACHS, 2008, p. 
37)

Diante desse cenário, a inclusão justa se converte como requisito central para o desenvolvimento. Se o adjetivo deve colocar atenção no aspecto mais essencial do paradigma de desenvolvimento, podemos falar então de desenvolvimento includente. (SACHS, 2008, p. 38)

A noção de desenvolvimento includente é tida por oposição ao padrão de crescimento excludente, perverso, concentrador (de renda e riqueza). Dois outros aspectos do crescimento excludente são:

\footnotetext{
- mercados de trabalho fortemente segmentados, que mantêm uma grande parcela da maioria trabalhadora confinada a atividades informais, ou condenada a extrair a sua subsistência precariamente da agricultura familiar de pequena escala, sem quase nenhum acesso à proteção social;

- fraca participação na vida política, ou completa exclusão dela de grandes setores da população, pouco instruída, suborganizada e absorvida na luta diária pela sobrevivência, sendo as mulheres, sujeitas à discriminação de gênero, as mais fortemente atingidas; (SACHS, pp. 38-39)
}

Observa-se, na cadeia do açaí, que o peconheiro possui pouca participação no mercado de trabalho, embora realize a atividade mais complexa e perigosa. A comercialização do fruto está segmentada de forma que os detentores de capital e meios de escoar a produção, conseguem obter lucros sem atuação direta na extração do açaí.

Por fim, para o êxito do desenvolvimento includente faz-se necessário garantir o pleno exercício dos direitos civis e políticos. No dizer de Sachs (2008, p. 39) a democracia é um valor verdadeiramente fundamental e garante também a transparência e a responsabilização (accountability) necessárias ao funcionamento dos processos de desenvolvimento.

Além disso, a alteração do modelo exploratório exige a combinação de várias políticas complementares: a - Explorar todas as oportunidades de crescimento induzido pelo emprego e com conteúdo zero ou baixo de importações; b - Desenhar políticas para consolidar e modernizar a agricultura familiar como parte de uma estratégia para estimular o desenvolvimento rural com base na pluriatividade da população rural, dando um salto na direção de uma civilização moderna baseada na biomassa (biodiversidade - biomassa biotecnologias); c- Promover ações afirmativas para melhorar a condição dos trabalhadores por conta própria e microempresas, para ajudá-los a sair da informalidade, e apoiar diversas formas de atividade empresarial compartilhada, com a finalidade de aumentar o poder de barganha e a competitividade dos pequenos produtores (passando pela competitividade

Rev. de Direito, Economia e Desenvolvimento Sustentável| e-ISSN: 2526-0057| Porto Alegre | v. 4 | n. 2 | p. 55 - 75 | Jul/Dez. 
espúria para a autêntica); criar uma entidade pública - mas não estatal - que atue como um planejador comprometido com os interesses dos pequenos produtores (o SEBRAE é um bom exemplo). (SACHS, 2008, pp. 19-20)

Na cadeia do açaí, é possível compreender a aplicação daquelas premissas da seguinte forma: a) aumento do número de postos de emprego formais, com eliminação do trabalho infantil e inclusão de mão de obra de indivíduos que não dominam a técnica, por meio da qualificação e aprendizado; b) políticas e incrementos tecnológicos para melhorar a produção familiar; formação de cooperativas de peconheiros com o objetivo de conseguir formar um grupo que consiga discutir preços, negociar junto ao mercado e conseguir receber incentivos governamentais e recursos financeiros, ou seja, formalizar o grupo de peconheiros; c) apoio de entidade voltada à proteção e incentivo da produção do fruto que funcione como fomentador e organizador das atividades, seja pelo oferecimento de qualificação técnica, seja pela formação dos peconheiros quanto aos seus direitos.

Com a aplicação das proposições acima, pretende-se fomentar o desenvolvimento endógeno, com melhoria quantitativa e qualitativa da condição de vida da população envolvida na cadeia produtiva do açaí.

\section{CONSIDERAÇÕES FINAIS}

A atividade extrativa do açaí em várzea realizada pelo peconheiro representa uma das atividades mais perigosas do país em virtude da existências de riscos desde o momento que o trabalhador sai de sua residência até o retorno.

Além disso, a cadeia oferece uma série de situações que, invariavelmente, se repetem em distintos municípios produtores do fruto, a exemplo da utilização de mão de obra infantil, a precariedade da atividade e a ocultação dos riscos suportados pelo peconheiros.

$\mathrm{Na}$ atividade de extração do fruto, toda a família do produtor participa, sem distinção específica quanto às atividades que serão desenvolvidas por cada um, embora seja comum o homem e a criança do sexo masculino subir no açaizeiro para colher os frutos e a mulher ser a responsável pelo esbulho. De toda forma, nada impede que todos façam as mesmas atividades.

Nota-se que, dentro do ambiente familiar, os membros da família contribuem como podem para que a produção e extração do fruto renda bons valores. Afinal, o valor obtido será

Rev. de Direito, Economia e Desenvolvimento Sustentável| e-ISSN: 2526-0057| Porto Alegre | v. 4 | n. 2 | p. 55 - 75 | Jul/Dez. 
revertido para todos eles. De toda sorte, importante destacar que a atividade, outrora familiar, tornou ares de atividade produtiva, com a crescente demanda nacional e internacional, o que exigiu reforços para a produção e alteração profunda no modo de sobrevivência da população local.

A despeito do crescimento econômico, identificou-se a inexistência de desenvolvimento na cadeia produtiva do açaí. É que, pelos aspectos teóricos, o desenvolvimento é entendido como o processo pelo qual aumenta-se a qualidade de vida das pessoas envolvidas em determinada atividade, não se confundindo e não se limitando ao crescimento meramente econômico.

Assim, desenvolvimento envolve o necessário desempenho dos direitos civis e políticos pela população, mas também tudo aquilo que lhe garanta felicidade. Diz-se desenvolvida a população quando os direitos são exercidos, não são tolhidos e o sentimento geral é de felicidade e realização.

Na cadeia do açaí não são identificadas as premissas acima. A população sofre por falta de acesso aos serviços públicos básicos, a exemplo de saúde e educação. Além disso, o peconheiro, em regra, não participa do processo de formação do preço de comercialização do produto e, portanto, não detém participação no mercado.

Em face disso, é necessária a alteração da dinâmica de produção para permitir um processo de mobilidade social, com elevação do poder econômico da comunidade diretamente interessada. Dentre desse contexto, faz-se necessário a implementação e aplicação de novos indicadores que considerem a melhoria de qualidade de vida do ser humano como principal objetivo do desenvolvimento, temática que será objeto de estudo em outro momento.

Como instrumento para alteração do modelo identificado, prepõe-se a aplicação do modelo de desenvolmento sustentável e includente, que concilia premissas ambientais, sociais, econômicas e políticas, e que garanta a real inclusão da população interessada nas vantagens propiciadas pelo crescimento econômico, seja pela garantia de acesso aos serviços públicos de qualidade, seja pelo aumento de sua participação nas decisões do mercado, seja pela sua qualificação técnica. De tal modo, será possível falar em desenvolvimento includente, de forma justa e efetiva.

O presente artigo não encerra a discussão sobre o assunto. Ao contrário, procura gerar mais indagações do que soluções propriamente ditas, por meio da reflexão de determinados pontos que devem ser analisados e debatidos, a exemplo quais seriam os indicadores 
adequados para mensurar o desenvolvimento dentro de uma cadeia exploratória local.

As indagações provocam inquietação e merecem estudo aprofundado de cada detalhe para que uma cadeia produtiva de tamanha importância econômica e social tenha como valor o respeito à dignidade da pessoa humana, com o reconhecimento e respeito dos direitos do peconheiro que viabilizem o seu desenvolvimento e garantam a melhoria de sua qualidade de vida.

\section{REFERÊNCIAS BIBLIOGRÁFICAS}

BERCOVICI, Gilberto. Constituição Econômica e Desenvolvimento: uma leitura a partir da Constituição de 1988. São Paulo: Malheiros, 2005.

FERREIRA, Pinto. Sociologia do Desenvolvimento. $5^{\text {a }}$ ed, rev. e at. São Paulo: Revista dos Tribunais, 1993.

FURTADO, Celso. Pequena Introdução ao Desenvolvimento Econômico: enfoque interdisciplinar. São Paulo: Editora Nacional, 1980.

GRAU, Eros Roberto. A Ordem Econômica na Constituição de 1988. $3^{\text {a }}$ ed. São Paulo: Malheiros, 1997.

INSTITUTO PEABIRU. “O Peconheiro": Diagnóstico das condições de trabalho do extrativista de açaí. Belém, Instituto Peabiru, 2016.

MARINHO, José Antônio Magalhães. Dinâmica das relações socioeconômicas e ecológicas no extrativismo do açaí: o caso do médio rio pracuúba, São Sebastião da Boa Vista, Marajó (PA). Belém, 2005. Dissertação de mestrado 186f.

PARÁ. Produção Agropecuária no Estado do Pará, Ano 2015. Secretaria de Estado de Desenvolvimento Econômico, Mineração e Energia. Disponível em <https://app.powerbi.com/view?r=eyJrIjoiMDU1ZDg5MjEtMzI4Yy00NTFILTlkMDUtODZl M2Y4OWMxY2NmIiwidCI6IjZmODE2NjdkLWNhZWMtNGUyMC05MzFlLTY5OGJjYjl mNmZlMyJ9 Acesso em 09 jul. 2018>

PERROUX, François. L'economie du Xxème siècle. 2Ème. Paris: Presses Universitaires de France, 1964.

SACHS, Ignacy. Desenvolvimento: includente, sustentável, sustentado. Rio de Janeiro: Garamond, 2008.

SEN, Amartya Kumar. Desenvolvimento como liberdade. Tradução Laura Teixeira Motta;

Rev. de Direito, Economia e Desenvolvimento Sustentável| e-ISSN: 2526-0057| Porto Alegre | v. 4 | n. 2 | p. 55 - 75 | Jul/Dez. 